\title{
Costs of formal and informal care at home for people with dementia: 'expert panel' opinions from staff and informal carers
}

Clarissa Giebel ${ }^{1, *}$, Susan Davies ${ }^{2}$, Paul Clarkson ${ }^{2}$, Caroline Sutcliffe ${ }^{2}$, and David Challis ${ }^{2}$ and members of the HoSt-D (Home Support in Dementia) Programme Management Group

${ }^{1}$ School of Health Sciences, University of East Anglia, Norwich, UK

${ }^{2}$ Personal Social Services Research Unit, University of Manchester, Manchester, UK

${ }^{*}$ Correspondence should be addressed to: Clarissa Giebel, Queen's Building, School of Health Sciences, University of East Anglia, Norwich, NR4 7TJ; Tel: 01603 593259; Email: C.Giebel@uea.ac.uk 


\section{ABSTRACT}

Effective home support in dementia is key in delaying nursing home admission. However, home support is frequently not tailored to the individual needs of people with dementia. Staff allocating home support services may not identify important care needs, which only be recognised by informal carers. The purpose of this study was to explore the balance of informal and formal home support and their associated costs from the perspectives of both informal carers and paid staff. Five case vignettes of people with dementia were designed based on an existing English data set from a European study into transition into long-term care (the RightTimePlaceCare programme), representing 42 per cent of the English sample. In total, 14 informal carers and 14 paid staff were consulted in separate groups, as expert panels, regarding their recommendations for home care services for each vignette. Care recommendations of carers and staff were costed based on nationally available unit costs and compared. Informal carers allocated fewer hours of care than staff. Personal and domestic home care and day care centres were the most frequently recommended formal services by both groups, and some vignettes of people with dementia were recommended for care home admission. The ratio of costs of informal versus formal support was relatively equal for paid staff, yet unbalanced from the perspectives of informal carers with a greater proportion of formal care costs. Recommendations from this study can help shape dementia care to be more tailored to the individual needs of people with dementia and their carers.

Keywords: dementia, home support, services, costs, carers 


\section{Introduction}

An estimated 850,000 people with dementia live in the UK, with two thirds living in their own home (Prince et al., 2014). Staying at home for longer is a primary objective for people with dementia and their carers. Home support provided by a combination of formal services and informal carers (Hajek et al., 2015; Wimo et al., 2002) can enable this to happen more effectively. This is also a goal of the National Dementia Strategy in England (Department of Health, 2009), as supporting a person with dementia in their own home costs less than living in a care home (Vossius et al., 2014; Wuebker et al., 2015). However, the balance between informal and formal care services at home and their costs, to enable this, has been relatively little explored.

Home support encompasses a myriad of services, and varies according to the needs of the person with dementia. In many cases home care provides help with activities of daily living (ADLs), such as bathing, dressing, or feeding, as these abilities start to deteriorate from the early stages of dementia onwards (Giebel et al., 2015a). Home support services also include befriending services, or transport to doctors' appointments or day care, whilst respite for carers is also an option to alleviate informal carer stress, a frequent result of the increased levels of caring duties (Sutcliffe et al., 2016). With a range of potential home support services available, it is important to understand the balance of informal and formal care that may be required, in order to determine the most effective service mix and the required balance of costs and inputs.

Although the economic costs of dementia have been estimated for the UK (Prince et al., 2014), more precise data are required, particularly that pertaining to later stages of the condition, taking into account a range of scenarios for people in different circumstances (Innes, 2009). Moreover, estimates of the balance between the costs of formal care, those arising from the services from professional and domiciliary support staff, and the costs of informal care, those from the inputs of carers' own time, are even less accurate, with the costs of informal care often underestimated. One review in this area estimates that the contribution of informal care to total care costs can range between 36 per cent and 85 per cent, depending on which elements are included (McDaid, 2001). However, one UK study found that such costs of informal care for people with dementia could be underestimated by 25 per cent for those living at home and as much as 40 per cent for those living with a carer (Schneider et al., 2003). Moreover, a high level of formal care inputs for certain cases may equate with high levels of informal care inputs, leading to the conclusion that formal care may supplement rather than substitute for informal care support (Schneider et al., 2003). Other, more recent work, has also estimated the balance between informal and formal care in different countries, with conflicting findings (Farre et al., 2016; Michalowsky et al., 2015). The more precise calculation of total care costs for people with dementia in different circumstances and the relative balance between formal and informal care costs is thus an important avenue for further enquiry.

This study was designed to address these to inform the development of an economic model of home support in dementia, as part of a programme of research on dementia care (Clarkson et al., 2016). The aims of this study were to (1) investigate the mix of inputs, in terms of home support recommended by professional staff (provided through the National Health Service (NHS) and social care services (e.g. Community Mental Health Teams, home/domiciliary care)) versus that 
recommended by informal carers to effectively support people with dementia at home; (2) specify the costs of such inputs for people with dementia living at home; and to (3) generate data on the costs of informal versus formal care recommended by each perspective, that of formal paid staff and informal carers. The research questions were therefore:

(1) Which inputs from health/social care services, and informal support, do informal carers consider important to support people with dementia at home effectively? How do these inputs vary from those suggested by formal, paid staff?

(2) What are the associated costs of the inputs specified by informal carers and by formal staff?

(3) What is the relative balance between the costs of informal versus formal support, suggested by formal paid staff and informal carers?

\section{Method}

\section{Participants and recruitment}

Ethical approval was obtained from the NRES Committee London - Stanmore (Reference 15/LO/1137) prior to starting the study. Convenience samples of informal carers and formal paid staff were recruited to the study. Informal carers of people with dementia were recruited via two local community centres, whilst an additional group of informal carers from a minority ethnic background was consulted for guidance. Informal carers were eligible to take part if they were caring for someone with dementia or have cared for someone with dementia in the past. The managers of the community centres approached carers during regular carer groups to enquire about their interest in the study. If carers were interested, they attended the study session at a specified date and time at their local community centre. Staff were recruited from Pennine Care NHS Foundation Trust through a senior manager who was part of the programme team and affiliated with the Trust. Staff were eligible to participate if they were working with people with dementia in their daily jobs. Those recruited to the study comprised different professional backgrounds in health and social care, including occupational therapists, community psychiatric nurses, social workers, and managers.

Participants were consulted as members of 'expert panels' (experts, respectively, by experience and training) to collect data on the inputs seen as necessary to support people with dementia at home effectively. From this, the relative balance between how costs may be shared between informal care and formal (NHS/social care) support was analysed. The consultations were undertaken through simulation exercises where participants were asked to outline the components they saw as necessary to support people in different circumstances, identified through 'case vignettes' (standard descriptions of real situations). Such an approach has been undertaken previously to inform policy developments for older people (Clarkson et al., 2006) and, for dementia, to inform decisions as to the most appropriate setting for support (Saks et al., 2015; Tucker et al., 2016). In total, 14 informal carers ( $n_{\text {group } 1}=6$ and $n_{\text {Group } 2=8)}$ and 14 staff $\left(n_{\text {group } 1}=6\right.$ and $\left.n_{\text {Group2 }}=8\right)$ participated in the study through 
four separate consultation groups. Informal carers had substantial levels of experience caring for their relative with dementia either in the past or currently. Staff were primarily female $(N=13)$ and had between 10 and 40 years of work experience in their roles.

\section{Development of case vignettes}

Based on a national subset of data ( $\mathrm{N}=61$; England) collected as part of a larger European programme of research (RightTimePlaceCare (RTPC)) (Verbeek et al., 2012), we created five case vignettes of people with dementia for use in the consultation groups with paid staff and informal carers. These case studies were broadly representative of people with dementia judged at risk of care home admission by a professional responsible for their care. For the purpose of creating the vignettes, we selected five variables from the data set which identified the person with dementia's level of cognition, dependency, challenging behaviours and informal carer burden. Cognition was assessed using the standardised Mini-Mental State Examination (S-MMSE) (Folstein et al., 1975; Molloy et al., 1991); Activities of Daily Living (ADL) by the Katz Index (Katz et al., 1963); behaviour by the Neuropsychiatric Inventory Questionnaire (NPI-Q) (Kaufer et al., 2000); and caregiver burden by the Zarit burden scale (Zarit et al., 1980). Cognitive impairment was categorised as low, medium and high based on S-MMSE scores of 24-20, 10-19, and 0-9 respectively. ADL impairment was categorised as low, medium and high based on respective Katz scores of 6, 5-3, and 2-0. Behavioural problems were rated as low with an NPI-Q score below 13 , and carer burden was rated as high with a Zarit score equal or above 46. Living situation was categorised according to whether the individual lived alone or not.

The categories from a combination of these five variables (Table 1) generated 72 possible case types in the RTPC dataset. Using the English data subset, 31 of the 72 case types were populated. From these 31 case types, we selected five which appeared most representative of the English subset of data collected for the RTPC project. These five case types represent 42 per cent $(\mathrm{N}=25)$ of people with dementia living at home but at risk of institutionalisation in this English sample.

From each case type, a case vignette was constructed, describing a hypothetical case study but incorporating realistic situations, based on the impairment level of categories within each case type (Table 2). The vignettes purposefully avoided professional language to enable informal carers, as well as paid staff, to equally understand the terminology used.

\section{[INSERT HERE TABLE 1 AND 2]}

\section{Procedure}

The study comprised four consultation groups: two with informal carers and two with professional staff. In addition, we conducted one consultation group with informal carers from a South Asian minority community (Leeds Touchstone Support Group), on one vignette, from all informal carers jointly $(n=6)$; these data were collected as a pilot test of the approach and to provide additional insights and are not analysed formally here. The consultation groups took place in community centres 
or charities, or in an NHS setting (Community Mental Health Team) and lasted approximately two hours. Prior to the consultation, written informed consent was obtained from the carers/members of staff. Participants were then presented with the five case vignettes, a guide to possible informal and formal care services (see Table 3), and, to collect data on the envisaged inputs for each case, were asked to complete a 'Care Plan' sheet detailing inputs throughout a 'typical week'. After having read through the vignettes individually, participants were asked to enter their suggested service use required by the person with dementia described in each vignette (ideally with a time commitment, for example 'an hour visit') on the sheet. The instruction to participants was to allocate the resources that could be used to meet the person's specific needs and thus create an appropriate package of care, taking into account the information provided in each vignette. Participants were asked to consider both formal paid help (e.g. from the NHS and/or social services) and informal care (e.g. specific inputs from the person living with or offering support to the person). Whilst each participant completed the exercise individually, they were given the opportunity to ask questions and confer if they wished. Data were collected between July 2015 and January 2016.

\section{[INSERT HERE TABLE 3]}

\section{Data analysis}

It was thought likely that each participant, from each constituent perspective, may identify slightly different inputs across a 'typical week' in the Care Plan Sheet for the five cases. The suggested use of services for each of the five vignettes was therefore analysed separately for informal carers and staff using descriptive statistics (means, standard deviations). For the purpose of analysis, day care centre use was translated into hours, with one day equaling six hours. Where participants stated that the person should be in a care home, this was translated into 24 hour care, seven days a week. Where 'no hours' of care input was mentioned in the Care Plan sheet, this was taken to imply that the person in the vignette required no formal or informal care.

The care plans from each participant were then costed according to an established costing methodology (Allen \& Beecham, 1993) by multiplying each identified input (e.g. 'home care visit') by its unit cost (see Table 3). Nationally available PSSRU unit costs (Curtis, 2014) were used. Informal care inputs were assigned unit costs based on a market value approach (the cost of the time of a paid staff member supplying the same or similar service as the carer). Different categories of informal carer inputs were used in the care plan exercise to enable these calculations, e.g. assisting the person with personal care, helping with tasks such as shopping or food preparation, and time spent supervising (Wimo \& Nordberg, 2007). These were calculated as costs per person (case type)/week for each participant. Costs were 'envisaged' and aggregated to provide an average (mean) cost per person/week. Differences in costs between informal and formal care, both for each case type and in total, from each constituent perspective (formal staff and informal carers), were then investigated. Finally, a ratio of costs of informal/formal care and the informal care contribution to total costs was calculated. 


\section{RESULTS}

\section{Suggested service use}

Table 4 shows the envisaged average weekly service use (inputs) by service type across the five vignettes, which represent 42 per cent of people with dementia living at home but at risk of institutionalisation in England. The most frequently suggested service type by both staff and informal carers was informal support, as well as personal home care and day care centres. Home health care teams, hospice/palliative care at home, accompanying services, voluntary organisations, and selfsupport groups were least recommended by formal staff and carers. Notably, caregiver support was considered by few formal staff and carers overall. On the whole, assessments by occupational therapists, speech and language therapists, dieticians, or continence nurses were recommended more by formal staff than by informal carers. It emerged that informal carers allocated fewer hours of care, particularly for informal carer support and paid personal and domestic home care. Informal carers suggested more hours of home support for hot meals and carergiver support than staff. This distribution of inputs, suggested by the 14 participants from each constituent perspective (formal staff and informal carers), resulted in similar amounts of total inputs for formal versus informal care; notably, informal carers tended to recommend slightly lower amounts than formal staff. The expert panels resulted in a range of total formal care inputs of between 49 and 442 hours per week being suggested by formal staff and between 62 and 360 hours per week suggested by the informal carers. The corresponding figures for informal care inputs were between 0 and 622 hours per week, suggested by formal staff and between 0 and 963 hours per week suggested by informal carers respectively.

In order to explore this wide range of suggested inputs, across the five different case types analysed, Table 5 shows the envisaged total service use per vignette, compared between formal staff and informal carers. Both formal staff and informal carers agreed that case type 2 required the largest amount of home support. However, formal staff judged case type 3 as requiring the least amount of home support, whereas informal carers suggested case type 4 as requiring the least amount. The greatest difference between informal carer and paid staff opinions was for case type 4, with informal carers suggesting almost half the amount of home support than paid staff. On average, formal staff suggested a total of 328 hours per week of support across the five case types, whereas informal carers suggested a total of 253 hours.

Some participants suggested that long-term care was more suitable than home support for case types 1,2, and 5, so for these cases the level of inputs was relatively higher. Participants suggested a range of other services such as assistive technology, monthly or bimonthly respite for carers and assessments by falls teams particularly for case types 2, 4, and 5 .

Further insights on recommendations for home support were obtained from an ethnic minority carer support group. Carers suggested that paid services such as hot meals provided by an ethnically-sensitive provider and befriending should be better accommodated to people from a minority ethnic background, due to dietary restrictions and cultural lifestyle differences. 


\section{Costs}

The variability in associated costs of care services for the five case vignettes are shown in Table 4. The highest costs were associated with hours of informal care. Day care and domestic and personal home care were also cost-intensive forms of support, whilst support groups, palliative care, home health care teams, and professional assessments contributed relatively little to overall costs. Care Plans for formal care input cost between $£ 1,126$ and $£ 7,349$ in total per week when completed by paid staff and between $£ 1,622$ and $£ 6,410$ per week when completed by informal carers. The corresponding figures for informal care costs were between $£ 0$ and $£ 14,928$ per week and between $£ 0$ and $£ 23,112$ per week from paid staff and informal carers respectively. This range of costs reflects the different judgements of each of the 14 participants from each perspective, concerning the different circumstances described in the case vignettes. On average (Table 4), the relative balance between the costs of informal versus formal support was $(£ 3,163 / 3,597) 0.89$ from the perspective of formal staff and $(£ 1,954 / 3,169) 0.62$ from the perspective of informal carers. Therefore, the proportion of informal care to total care costs, on average over these different case types, was $47 \%$ from the point of view of formal staff and $38 \%$ from the perspective of informal carers.

Calculating these figures only from each constituent perspective; that is, taking judgements of formal care costs only from formal staff and informal care costs only from informal carers, results in a balance between the costs of informal and formal support of $(£ 1,954 / 3,597) 0.54$. Calculated in this way, the contribution of informal care to total care costs was 35\% [£1,954/(£1,954+3,597)].

Table 5 shows the envisaged total costs, per vignette, compared between formal staff and informal carers. From the inputs elicited, informal carers judged that case type 5 , characterised by high ADL dependency and behavioural problems, would incur the highest costs (a mean of $£ 1,386$ ). Formal staff, however, considered case type 1, living alone and characterised by high carer burden, as incurring the highest costs (a mean of $£ 1,853$ ). Overall, total costs were judged to be very similar, from each of the perspectives, with formal staff, on average, judging costs to be relatively higher than informal carers. There was, on average, a $£ 1,637$ per week difference between total costs suggested by formal staff and informal carers.

\section{[INSERT HERE TABLE 4 AND 5]}

\section{Discussion}

This study provides new insights into the balance of formal and informal home support for people with dementia, and their associated indicative costs, from the perspectives of paid staff and informal carers. Evidence suggests both variations and similarities between the two perspectives, with findings helping to identify potential needs for individualised home support.

Informal carers offered different judgements as to which components of health and social care services should be provided to people in the moderate to later stages of dementia, compared to paid staff. The provision of hot meals and increased carer support emerged as more frequently identified by informal carers. Similarly, although day care was considered important by both paid staff and 
informal carers, the latter group put more value on this resource. In contrast, informal carers suggested fewer hours of care for personal and domestic services compared to paid staff. This might be the result of personal experiences of providing the majority of care (in the form of informal care), which is also grounded in evidence (Hajek et al., 2015; Michalowsky et al., 2015). On the other hand, paid carers were more likely to suggest additional assessments by speech and language therapists or dieticians for example, which possibly is due to their being more informed and aware of these services. By contrast, carers, and people with dementia, are frequently reported to lack awareness of services as well as the knowledge on how to access these (Giebel et al., 2015b; Sutcliffe et al., 2015). Evidence from the RTPC project and the availability of dementia care in Europe (Bökberg et al., 2015) suggest that home care is too general across Europe, with too little scope for individualised services. Findings from the present study might offer some suggestions of how dementia care could be more individualised, with a balance between formal and informal care, depending on the needs of the PwD.

As regards the relative disparity between informal and formal costs, there were a number of interesting differences, according to the different constituent perspectives. Although both paid staff and informal carers recommended informal care input for all five case types, there was nevertheless an imbalance between informal and formal care costs from the different points of view arising from each perspective. Paid staff reported a relatively equal balance of care costs for both types of care (0.89), whereas informal carers placed a greater weight on paid care than informal care $(0.62)$, less in relation to personal and domestic home care, but more so for day care and the provision of hot meals. Indeed, in a recent literature review (Tretteteig et al., 2016), day care is shown to benefit carers. These real data stand in contrast to recommendations from the expert panels of informal carers and paid staff in the present study, indicating that some forms of home support, such as day care, should be employed to a greater extent than currently the case.

In terms of the contribution of informal care costs to overall costs, the findings of the present study show consistency but also discrepancy with the wider literature. The Alzheimer's Society reports that unpaid care in the UK is equivalent to $£ 11.6$ billion, which approximates to 44 percent of the total cost of dementia care (Prince et al., 2014). Indeed, informal care represents the largest contributor to care costs in several recent studies (Farre et al., 2016; Michalowsky et al., 2015). In a real-cost analysis of the balance of formal versus informal care costs for community-dwelling people with dementia living in Germany, the cost ratio of formal versus informal care was one to ten $(1,646 €$ and $16,473 €$ ) (Michalowsky et al., 2015). Moreover, in a Spanish population of people with dementia living in the community (Farre et al., 2016), average informal carer costs were 1214€ (SD 902) per month, from an average total of $1956 €$ (SD 1463) a month, or $62 \%$. In the present study, the informal care contribution depended on the perspective from which it was judged; $47 \%$ from the perspective of formal staff, $38 \%$ from that of informal carers, and 35\% from the congruent constituent perspective, i.e. only from the viewpoint of the person responsible for the care input, formal care costs only from formal staff and informal care costs only from informal carers. Therefore, the present findings are consistent with other UK evidence but diverge from real costs in European studies (Farre et al., 2016; Michalowsky et al., 2015). In the future, in the UK, in a constrained economic environment, this balance is likely to change. Pressures on formal care services may mean a reduction in the 
contribution of formal care costs to overall costs. Whether such a change would be offset by increases in the contribution of informal costs is uncertain, as pressures on informal carers may mean they cannot substitute for deficiencies in formal care. Such a scenario is likely to result in unsustainable community-based care and may mean long-term nursing home case is used to a greater extent, thus raising formal care costs.

\section{Limitations}

The study was subject to some limitations. The sample of informal carers and paid staff was relatively small due to the exploratory and descriptive nature of the study. It's purpose was to consult with 'expert panels' (either by experience or training) to explore their respective decisions on the appropriate inputs required to support people with dementia at home effectively and use the results to inform the development of an economic model of home support in dementia. The case types were based on a subset of people with dementia judged to be on the margins of transition into long-term care, and did not necessarily represent people with mild or early stage dementia who require little or no home support. However, the vignettes described people with dementia in a variety of circumstances displaying various levels of care needs, and are thus representative of moderate and more advanced stages of dementia. In addition, evidence from this study benefits from a greater representativeness by involving members of an ethnic minority group. An additional limitation might be that some informal carers did not specify the precise hours of support for some services, so that a judgement was made in order to calculate indicative costs. This may have resulted in under-reporting of the amount of, for example, informal carer inputs. A final limitation concerns the nature of costs in this study. This study used indicative costs, calculated from the judgements of key players concerning their opinions as to the most effective way to support people with dementia, in different circumstances, at home. They are therefore not real costs and are from a particular perspective; they do not represent full societal costs and do not include the resources expended on accommodation and other social costs, particularly by informal carers (Drummond et al., 2005).

\section{Conclusions}

This study offered insights into the balance of informal and formal home support and their indicative costs from the perspectives of major stakeholders, informal carers and paid staff. The disparity in suggested informal and formal care provision from both these perspectives suggest that dementia care could benefit from taking greater account of the different perspectives of stakeholders, e.g. both paid staff and informal carers, in identifying the individual needs of people with dementia and their carers. The importance of implementing a range of home support services was highlighted; in particular carer support, day care, and hot meals service, supporting findings from a recent European study (Bökberg et al., 2015). 


\section{Declaration of Conflicting Interest}

The author(s) declared no potential conflicts of interest with respect to the research, authorship, and/or publication of this article.

\section{Funding}

This research was funded by the National Institute for Health Research (NIHR) under its Programme Grants for Applied Research scheme (Grant Reference Number: DTC-RP-PG-0311-12003).

\section{Acknowledgements}

We wish to thank all carers and staff who took part in this study. We wish to thank staff in Pennine Care NHS Foundation Trust for acting as members of expert panels to undertake the study. We also wish to acknowledge the support we received from Together Dementia Support in South Manchester and from Bury Carers Centre in Greater Manchester, as well as Touchstone Support in Leeds, in recruiting carers. Other members of the Programme Management Group are: Professor Martin Orrell (University of Nottingham), Brenda Roe (Edge Hill University), lan Russell (Swansea University), Fiona Poland (University of East Anglia), Narinder Kapur (University College London), Professor Chris Roberts, Professor Linda Davies, Professor David Jolley and Dr Jane Hughes (University of Manchester), Jean Tottie (Uniting Carers); and Reagan Blyth (Pennine Care NHS Foundation Trust). The views expressed are those of the authors and not necessarily those of the NHS, the NIHR or the Department of Health. 


\section{References}

Allen, C., \& Beecham, J. (1993). Costing services: ideals and reality. In Netten, A. and Beecham, J. (eds), Costing Community Care: Theory and Practice. Ashgate, Aldershot, Hampshire, 25-42.

Bakker, C., de Vugt, M.E., van Vliet, D., et al. (2013). The Use of Formal and Informal care in Early Onset Dementia: Results from the NeedYD Study. The American Journal of Geriatric Psychiatry, 21(1), 37-45.

Bökberg, C., Ahlstrom, G., Leino-Kilpi, H., et al. (2015). Care and Service at Home for Persons with Dementia in Europe. Journal of Nursing Scholarship, 47(5), 407-416.

Clarkson, P., Giebel, C.M., Larbey, M., Roe, B., Challis, D., Hughes, J., Jolley, D., Poland, F., \& Russell, I. (2016). A protocol for a systematic review of effective home support to people with dementia and their carers: components and impacts. Journal of Advanced Nursing, 72(1), 186196.

Clarkson, P., Hughes, J., \& Challis, D. (2005). The potential impact of changes in public funding for residential and nursing home care in the United Kingdom: the Residential Allowance. Ageing and Society, 25, 159-180.

Curtis, L. (2014). Unit Costs of Health and Social Care 2014. Kent: University of Kent, PSSRU.

Drummond, M.F., Sculpher, M.J., Torrance, G.W., O'Brien, B. \& Stoddart, G.L. (2005). Methods for the Economic Evaluation of Health Care Programmes, 3rd Edition. Oxford: Oxford University Press.

Farre, M., Haro, J.M., Kostov, B., Alvira, C., Rico, E., Miguel, S., Cabrera, E., \& Zabalegui, A. (2016). Direct and indirect costs and resource use in dementia care: A cross-sectional study in patients living at home. International Journal of Nursing Studies, 55, 39-49.

Gibson, A.K., Anderson, K.A., \& Acocks, S. (2014). Exploring the Service and Support Needs of Families With Early-Onset Alzheimer's Disease. American Journal of Alzheimer's disease \& Other Dementias, 29(7), 596-600.

Giebel, C.M., Sutcliffe, C., \& Challis, D. (2015a). Activities of daily living and quality of life across different stages of dementia: a UK study. Aging \& Mental Health, 19(1), 63-71.

Giebel, C.M., Zubair, M., Jolley, D., Bhui, K., Purandare, N., Worden, A., \& Challis, D. (2015b). South Asian Older Adults with Memory Impairment: Improving Assessment and Access to Dementia Care. International Journal of Geriatric Psychiatry, 30(4), 345-356.

Hajek, A., Brettschneider, C., Ernst, A., Posselt, A., Wiese, B., Prokein, J., Weyerer, S., et al. (2015). Longitudinal predictors of informal and formal caregiving time in community-dwelling dementia patients. Social Psychiatry and Psychiatric Epidemiology, doi: 10.1007/s00127-015-1138-7

Innes, A. (2009). Dementia Studies. London: Sage.

Katz, S. (1983). Assessing self-maintenance: Activities of daily living, mobility and instrumental activities of daily living. Journal of the American Geriatrics Society, 31(12), 721-726.

Kaufer, D.I., Cummings, J.L., Ketchel, P., Smith, V., MacMillan, A., Shelley, T., Lopez, O.L., \& DeKosky, S.T. (2000). Validation of the NPI-Q, a brief clinical form of the neuropsychiatric inventory. Journal of Neuropsychiatry \& Clinical Neurosciences, 12(2), 233-239.

McDaid, D. (2001). Estimating the costs of informal care for people with Alzheimer's disease: methodological and practical challenges. International Journal of Geriatric Psychiatry, 16, 400405.

Michalowsky, B., Thyrian, J.R., Eichler, T., Hertel, J., Wucherer, D., Flessa, S., \& Hoffmann, W. (2015). Economic Analysis of Formal Care, Informal Care, and Productivity Losses in Primary Care Patients who Screened Positive for Dementia in Germany. Journal of Alzheimer's Disease, 50(1), 47-59.

Molloy, D.W, Alemayehu, E., \& Roberts, R. (1991). Reliability of a Standardized Mini-Mental State Examination compared with the traditional Mini-mental State Examination. American Journal of Psychiatry, 148, 102-105.

Prince, M., Knapp, M., Guerchet, M., McCrone, P., Prina, M., Comas-Herrera, A., Wittenberg, R., Adelaja, B., Hu, B., et al. (2014). Dementia UK: Update. London: Alzheimer's Society. 
Saks, K., Tiit, E.M., Verbeek, H., Raamat, K., Armolik, A., Leibur, J., et al. (2015). Most appropriate placement for people with dementia: individual experts' vs. expert groups' decisions in eight European countries. Journal of Advanced Nursing, 71(6),1363-1377.

Schneider, J., Hallam, A., Islam, M.K., Murray, J., Foley, B., Atkins, L., Banerjee, S. \& Mann, A. (2003). Formal and informal care for people with dementia: variations in costs over time. Ageing and Society, 23, 303-326.

Sutcliffe, C.L., Giebel, C.M., Jolley, D., \& Challis, D. (2016). Experience of burden in carers of people with dementia at the margins of long-term care. International Journal of Geriatric Psychiatry, 31(2), 101-108.

Sutcliffe, C.L., Roe, B., Jasper, R., Jolley, D., \& Challis, D. (2015). People with dementia and carers' experiences of dementia care and services: Outcomes of a focus group study. Dementia, 14(6), 769-787.

Tretteteig, S., Vatne, S., \& Rokstad, A.M.M. (2016). The influence of day care centres for people with dementia on family caregivers: an integrative review of the literature. Aging \& Mental Health, 20(5), 450-462.

Tucker, S., Brand, C., Sutcliffe, C., Challis, D., Saks, K., Verbeek, H., Cabrera, E., Karlsson, S., LeinoKilpi, H., Stephan, A., \& Soto, M.E. on behalf of the RightTimePlaceCare Consortium (2016). What makes institutional long-term care the most appropriate setting for people with dementia? Exploring the influence of client characteristics, decision-maker attributes and country in eight European nations. Journal of the American Medical Directors Association, 17(5), 465e9-465e 15.

Verbeek, H., Meyer, G., Leino-Kilpi, H., Zabalegui, A., Hallberg, I.R., Saks, K., et al. (2012). RightTimePlaceCare Consortium. (2012). A European study investigating patterns of transition from home care towards institutional dementia care: The protocol of a RightTimePlaceCare study. BMC Public Health, 12, 68.

Vossius, C., Rongve, A., Testad, I., Wimo, A., \& Aarsland, D. (2014). The Use and Costs of Formal Care in Newly Diagnosed Dementia: A Three-Year Prospective Follow-Up Study. The American journal of Geriatric Psychiatry, 22(4), 381-388.

Wimo, A., \& Nordberg, G. (2007). Validity of assessments of time-comparisons of direct observations and estimates of time by the use of the RUD (Resource Utilization in Dementia) - instrument. Archives of Gerontology and Geriatrics, 44, 71-81.

Wimo, A., von Strauss, E., Nordberg, G., Sassi, F., \& Johansson, L. (2002). Time spent on informal and formal care for persons with dementia in Sweden. Health Policy, 61, 255-268.

Wuebker, A., Zwakhalen, S.M.G., Challis, D., Suhonen, R., Karlsson, S., Zabalegui, A., Soto, M., Saks, K., \& Sauerland, D. (2015). Costs of care for people with dementia just before and after nursing home placement: primary data from eight European countries. European Journal of Health Economics, 16, 689-707.

Zarit, S.H., Reever, K.E., \& Bach-Peterson, J. (1980). Relatives of the impaired elderly: Correlates of feelings of burden. The Gerontologist, 20(6), 649-55. 


\section{Author Biographies}

Clarissa M Giebel is a Postdoctoral Research Associate at the School of Health Sciences at the University of East Anglia and finalising her PhD in Psychology at the University of Manchester. She has over five years of research experience in dementia and has been involved in research into longterm care transition, and motivation and performance of everyday activities in dementia, amongst others.

Sue Davies is a Research Associate at the Personal Social Services Research Unit at the University of Manchester. She has a background in statistics, the analysis of routinely collected data and has experience managing large data sets.

Dr Paul Clarkson is Research Fellow, Personal Social Services Research Unit, University of Manchester and Senior Fellow, National Institute for Health Research (NIHR), School for Social Care Research. He has undertaken and managed applied health and social care research in the fields of long-term care and mental health, dementia support, assessment interventions, policy and programme evaluation and health economic evaluation.

Caroline Sutcliffe is a Research Associate with a psychology background. Her research interests encompass a broad area of study including residential and nursing home care, health and community care of older people with mental health problems and people with dementia and their carers.

Prof David Challis is Professor of Community Care Research, Director of PSSRU, University of Manchester, Associate Director of the National Institute for Health Research (NIHR) School for Social Care Research, NIHR Senior Investigator and has an Honorary Contract with Manchester Mental Health and Social Care Trust. He is responsible for a range of research studies and policy evaluations in health and social care in the UK and other countries. 
Table 1. Attributes used in the creation of case vignettes

\begin{tabular}{|l|l|l|}
\hline Variable & Category & Definition \\
\hline Cognitive impairment & Low & S-MMSE score 20-24 \\
\cline { 2 - 3 } & Medium & S-MMSE score 10-19 \\
\cline { 2 - 3 } & High & S-MMSE score 0-9 \\
\hline \multirow{3}{*}{ ADL dependency } & Low & Katz score 6 \\
\cline { 2 - 3 } & Medium & Katz score 3-5 \\
\cline { 2 - 3 } & High & Katz score 0-2 \\
\hline Problem behaviours & Low & NPI-Q $<13$ \\
\cline { 2 - 3 } & High & NPI-Q $\geq 13$ \\
\hline \multirow{2}{*}{ Living situation } & Alone & Living alone \\
\cline { 2 - 3 } & Not alone & Living with carer/relative \\
\hline Carer burden & Low & Zarit score $<46$ \\
\cline { 2 - 3 } & High & Zarit score $\geq 46$ \\
\hline
\end{tabular}

Note: Categories from RTCP data across Europe $(\mathrm{N}=2014)$

$A D L=$ Activities of daily living; NPI-Q= Neuropsychiatric Inventory Questionnaire; S-MMSE=Standardised Mini Mental State Examination. 
Table 2. Definition of case vignettes

\begin{tabular}{|l|c|c|c|c|c|c|}
\hline $\begin{array}{c}\text { Case } \\
\text { vignette }\end{array}$ & $\begin{array}{c}\text { Cognitive } \\
\text { impairment }\end{array}$ & $\begin{array}{c}\text { ADL } \\
\text { dependency }\end{array}$ & $\begin{array}{c}\text { Behavioural } \\
\text { problems }\end{array}$ & $\begin{array}{c}\text { Living } \\
\text { situation }\end{array}$ & $\begin{array}{c}\text { Carer } \\
\text { burden }\end{array}$ & Prevalence $^{\mathbf{1}}$ \\
\hline $1-$ Mrs. B & Low & Medium & Low & Alone & High & $7 \%$ \\
\hline $2-$ Mrs T & Medium & Medium & Low & Not alone & Low & $13 \%$ \\
\hline $3-$ Mr. Q & Medium & Medium & Low & Not alone & Low & $7 \%$ \\
\hline $4-$ Mrs. D & High & Medium & Low & Not alone & Low & $10 \%$ \\
\hline $5-$ Mrs. C & High & High & High & Not alone & Low & $5 \%$ \\
\hline
\end{tabular}

$\mathrm{ADL}=$ Activities of daily living

1 Percentage of people with dementia living at home but judged at risk of institutionalisation in the UK data subset. 
Table 3. List of suggested services and their unit costs

\begin{tabular}{|c|c|c|c|c|}
\hline \multicolumn{5}{|c|}{ Formal Services } \\
\hline Code & Definition & Cost & Definition of unit cost used & Source \\
\hline HC-P & $\begin{array}{l}\text { Home care with personal care: Help provided with } \\
\text { personal care - washing, dressing etc. at home by } \\
\text { paid domiciliary care worker. }\end{array}$ & $\begin{array}{l}£ 24 \text { per hour } \\
\text { weekday } \\
£ 25 \text { per hour } \\
\text { weekend }\end{array}$ & $\begin{array}{l}\text { Home care worker- based on the price } \\
\text { multipliers for independent sector home } \\
\text { care provided for social services. Face } \\
\text { to face contact } 2013 / 14 \text {. }\end{array}$ & $\begin{array}{l}\text { Unit Cost of Health and } \\
\text { Social Care } 2014 \text { (11.6, pg } \\
210)\end{array}$ \\
\hline HC-D & $\begin{array}{l}\text { Home care with domestic care: Help provided with } \\
\text { activities such as preparing meals, managing } \\
\text { medications, housework etc. at home by paid } \\
\text { domiciliary care worker. }\end{array}$ & $\begin{array}{l}£ 24 \text { per hour } \\
\text { weekday } \\
£ 25 \text { per hour } \\
\text { weekend }\end{array}$ & $\begin{array}{l}\text { Home care worker- based on the price } \\
\text { multipliers for independent sector home } \\
\text { care provided for social services. Face } \\
\text { to face contact } 2013 / 14 \text {. }\end{array}$ & $\begin{array}{l}\text { Unit Cost of Health and } \\
\text { Social Care } 2014 \text { (11.6, pg } \\
210)\end{array}$ \\
\hline $\mathrm{HN}$ & $\begin{array}{l}\text { Home nursing care: Nursing care provided at home, } \\
\text { such as wound dressing, injections, by a nurse. }\end{array}$ & $\begin{array}{l}£ 66 \text { per hour of } \\
\text { patient related } \\
\text { work }\end{array}$ & $\begin{array}{l}\text { Community nurse (includes district } \\
\text { nursing sister, district nurse) 2013/2014 } \\
\text { (includes qualifications) }\end{array}$ & $\begin{array}{l}\text { Unit Cost of Health and } \\
\text { Social Care } 2014 \text { (10.1, pg } \\
187)\end{array}$ \\
\hline HN-D & $\begin{array}{l}\text { Specialised home nursing care for people with } \\
\text { dementia: Supervision, support, treatment and } \\
\text { monitoring by Community Dementia/Psychiatric } \\
\text { Nurse. }\end{array}$ & $\begin{array}{l}£ 74 \text { per hour of } \\
\text { patient related } \\
\text { work }\end{array}$ & $\begin{array}{l}\text { Nurse specialist (community) 2013/2014 } \\
\text { (includes qualifications) }\end{array}$ & $\begin{array}{l}\text { Unit Cost of Health and } \\
\text { Social Care } 2014(10.4, \mathrm{pg} \\
190)\end{array}$ \\
\hline DCG & $\begin{array}{l}\text { Day care general for older people: Agency providing } \\
\text { social activities \& activities engaging physical, mental } \\
\text { and intellectual abilities, during daytime. }\end{array}$ & $\begin{array}{l}£ 12 \text { per client } \\
\text { hour } \\
£ 42 \text { per client } \\
\text { session ( } 3.5 \\
\text { hours) }\end{array}$ & $\begin{array}{l}\text { Local authority day care for older people } \\
2013 / 14 \text { (includes capital costs). }\end{array}$ & $\begin{array}{l}\text { Unit Cost of Health and } \\
\text { Social Care } 2014(1.6, \mathrm{pg} 38)\end{array}$ \\
\hline DC-D & $\begin{array}{l}\text { Day care specialised in dementia care: Agency with } \\
\text { specialised staff providing social activities \& activities } \\
\text { dedicated to people with dementia, engaging } \\
\text { cognitive ability, such as memory, during daytime. }\end{array}$ & $\begin{array}{l}£ 12 \text { per client } \\
\text { hour } \\
£ 42 \text { per client } \\
\text { session ( } 3.5 \\
\text { hours) }\end{array}$ & $\begin{array}{l}\text { Local authority day care for older people } \\
2013 / 14 \text { (includes capital costs). }\end{array}$ & $\begin{array}{l}\text { Unit Cost of Health and } \\
\text { Social Care } 2014(1.6, \mathrm{pg} 38)\end{array}$ \\
\hline HHCT & $\begin{array}{l}\text { Home health care team (general, not specialised in } \\
\text { dementia care): Health care provided in the patient's } \\
\text { own home by a multidisciplinary team. The team is in } \\
\text { charge of the treatment and monitoring of the patient } \\
\text { with dementia and his/her caregiver. }\end{array}$ & $\begin{array}{l}£ 41 \text { hour per } \\
\text { team member } \\
£ 132 \text { per face to } \\
\text { face contact }\end{array}$ & $\begin{array}{l}\text { NHS CMHT for older people with mental } \\
\text { health problems } 2013 / 14 \\
\text { Mean average weighted cost per face to } \\
\text { face contact for all CMHT for older } \\
\text { people }\end{array}$ & $\begin{array}{l}\text { Unit Cost of Health and } \\
\text { Social Care } 2014 \text { (12.1, pg } \\
217) \\
\text { DH NHS Reference Cost } \\
2012-2013\end{array}$ \\
\hline RC-H & $\begin{array}{l}\text { Respite care at home: Care at home for relief to } \\
\text { informal caregivers who are caring for a family }\end{array}$ & $\begin{array}{l}£ 24 \text { per hour } \\
\text { weekday }\end{array}$ & $\begin{array}{l}\text { Home care worker- based on the price } \\
\text { multipliers for independent sector home }\end{array}$ & $\begin{array}{l}\text { Unit Cost of Health and } \\
\text { Social Care } 2014(11.6, \mathrm{pg}\end{array}$ \\
\hline
\end{tabular}




\begin{tabular}{|c|c|c|c|c|}
\hline & member/close friend, e.g. 'sitting service'. & $\begin{array}{l}£ 25 \text { per hour } \\
\text { weekend }\end{array}$ & $\begin{array}{l}\text { care provided for social services. Face } \\
\text { to face contact } 2013 / 14 \text {. }\end{array}$ & 210) \\
\hline HPC-H & $\begin{array}{l}\text { Hospice/Palliative care at home: Hospice is a type of } \\
\text { care of a terminally ill patient's symptoms. These } \\
\text { symptoms can be physical, emotional, spiritual or } \\
\text { social in nature. It includes palliative care for the } \\
\text { incurably ill given to those living in their own homes. }\end{array}$ & $\begin{array}{l}£ 79 \text { per hour of } \\
\text { service }\end{array}$ & $\begin{array}{l}\text { Hospice Rapid Response Service - } \\
\text { Provide intense care in patients home as } \\
\text { crisis arises 2013/14 }\end{array}$ & $\begin{array}{l}\text { Unit Cost of Health and } \\
\text { Social Care } 2014(7.9, \mathrm{pg} \\
123)\end{array}$ \\
\hline HM & $\begin{array}{l}\text { Home delivered meals/Catering service: A service } \\
\text { that delivers cooked meals to disabled and/or older } \\
\text { people in their homes. }\end{array}$ & $£ 6.60$ per meal & $\begin{array}{l}\text { Average cost of 'meals on wheels' for } \\
\text { the local authority } 2012 / 13\end{array}$ & $\begin{array}{l}\text { Unit Cost of Health and } \\
\text { Social Care } 2014(8.1, \mathrm{pg} \\
127)\end{array}$ \\
\hline TR & $\begin{array}{l}\text { Transport service: } \\
\text { persons. }\end{array}$ & $£ 45.58$ per activity & $\begin{array}{l}\text { National average unit cost of NHS Trusts } \\
\text { Patient Transport Services: Outpatient. } \\
2009 / 08 \text {, uprated to } 2013 / 2014 \text { prices } \\
\text { using Bank of England calculator }\end{array}$ & $\begin{array}{l}\text { NHS National Schedule of } \\
\text { Reference Costs Year } \\
2008 / 09\end{array}$ \\
\hline AC & $\begin{array}{l}\text { Accompanying service: Service for accompanying a } \\
\text { person to appointments, providing transportation } \\
\text { and/or shopping etc. }\end{array}$ & $\begin{array}{l}£ 50 \text { per hour of } \\
\text { client related work }\end{array}$ & Family support worker $2013 / 14$ & $\begin{array}{l}\text { Unit Cost of Health and } \\
\text { Social Care } 2014 \text { (8.1,pg } \\
127)\end{array}$ \\
\hline VO & $\begin{array}{l}\text { Voluntary organisation: Unpaid organisation providing } \\
\text { care and service to persons with dementia, e.g. } \\
\text { Alzheimer's Society. }\end{array}$ & $\begin{array}{l}£ 50 \text { per hour of } \\
\text { client related work }\end{array}$ & Family support worker $2013 / 14$ & $\begin{array}{l}\text { Unit Cost of Health and } \\
\text { Social Care } 2014 \text { (8.1,pg } \\
127)\end{array}$ \\
\hline SH & $\begin{array}{l}\text { Self-help organisation/Self-support group: The } \\
\text { organisation may offer individual support by other } \\
\text { people with dementia. }\end{array}$ & $\begin{array}{l}£ 50 \text { per hour of } \\
\text { client related work }\end{array}$ & Family support worker $2013 / 14$ & $\begin{array}{l}\text { Unit Cost of Health and } \\
\text { Social Care } 2014 \text { (8.1, pg } \\
127)\end{array}$ \\
\hline CS & $\begin{array}{l}\text { Caregiver support: Organisation where professionals } \\
\text { provide support individually and/or in groups, and } \\
\text { provide home visits to informal Caregivers, e.g. } \\
\text { advice, how to cope with difficulties. }\end{array}$ & $\begin{array}{l}£ 50 \text { per hour of } \\
\text { client related work }\end{array}$ & Family support worker $2013 / 14$ & $\begin{array}{l}\text { Unit Cost of Health and } \\
\text { Social Care } 2014 \text { (8.1,pg } \\
127)\end{array}$ \\
\hline \multicolumn{5}{|l|}{ OTHER } \\
\hline $\mathrm{CH}$ & $\begin{array}{l}\text { Care home: admission to a care/nursing home for } \\
24 \mathrm{hr} \text { care; for those who it is felt are unable to be } \\
\text { cared for at home }\end{array}$ & $\begin{array}{l}£ 753 \text { per } \\
\text { permanent } \\
\text { resident week }\end{array}$ & $\begin{array}{l}\text { Establishment cost plus personal living } \\
\text { expenses }\end{array}$ & $\begin{array}{l}\text { Unit Cost of Health and } \\
\text { Social Care } 2014(1.1, \mathrm{pg} 33)\end{array}$ \\
\hline OT & $\begin{array}{l}\text { Occupational Therapist for assessment visits and/or } \\
\text { to arrange assistance in the home }\end{array}$ & $£ 36$ per hour & $\begin{array}{l}\text { NHS Community Occupational } \\
\text { Therapist, } 2013 / 14\end{array}$ & $\begin{array}{l}\text { Unit Cost of Health and } \\
\text { Social Care } 2014 \text { (8.1,pg } \\
180)\end{array}$ \\
\hline SPL & $\begin{array}{l}\text { Speech and Language Therapist for assistance and } \\
\text { training }\end{array}$ & $£ 36$ per hour & $\begin{array}{l}\text { Community Speech and Language } \\
\text { Therapist, one to one contact } 2013 / 14\end{array}$ & $\begin{array}{l}\text { Unit Cost of Health and } \\
\text { Social Care } 2014 \text { (8.1,pg } \\
\text { 181) }\end{array}$ \\
\hline CON & Continence Advisor for assistance and advice & $£ 74$ per hour of & Nurse specialist (community) 2013/2014 & Unit Cost of Health and \\
\hline
\end{tabular}




\begin{tabular}{|c|c|c|c|c|}
\hline & & $\begin{array}{l}\text { patient related } \\
\text { work }\end{array}$ & (includes qualifications) & $\begin{array}{l}\text { Social Care } 2014 \text { (10.4, pg } \\
190)\end{array}$ \\
\hline DIET & Dietician for assistance and advice & $£ 37$ per hour & Hospital Dietician & $\begin{array}{l}\text { Unit Cost of Health and } \\
\text { Social Care } 2014(10.4, \mathrm{pg} \\
\text { 238) }\end{array}$ \\
\hline \multicolumn{5}{|c|}{ Informal caregiving } \\
\hline Code & Definition & Cost & Definition of cost & Source \\
\hline INF-P & $\begin{array}{l}\text { Informal Personal: Carer assisting the person with } \\
\text { tasks such as toileting, eating, dressing, grooming, } \\
\text { and bathing. }\end{array}$ & $\begin{array}{l}£ 24 \text { per hour } \\
\text { weekday } \\
£ 25 \text { per hour } \\
\text { weekend }\end{array}$ & $\begin{array}{l}\text { Home care worker- based on the price } \\
\text { multipliers for independent sector home } \\
\text { care provided for social services. Face } \\
\text { to face contact. }\end{array}$ & $\begin{array}{l}\text { Unit Cost of Health and } \\
\text { Social Care } 2014 \text { (11.6, pg } \\
210)\end{array}$ \\
\hline INF-D & $\begin{array}{l}\text { Informal Domestic: Carer assisting the person with } \\
\text { tasks such as shopping, food preparation, } \\
\text { housekeeping, laundry, transportation, taking } \\
\text { medication and managing finances. }\end{array}$ & $\begin{array}{l}£ 24 \text { per hour } \\
\text { weekday } \\
£ 25 \text { per hour } \\
\text { weekend }\end{array}$ & $\begin{array}{l}\text { Home care worker- based on the price } \\
\text { multipliers for independent sector home } \\
\text { care provided for social services. Face } \\
\text { to face contact. }\end{array}$ & $\begin{array}{l}\text { Unit Cost of Health and } \\
\text { Social Care } 2014 \text { (11.6, pg } \\
210)\end{array}$ \\
\hline $\begin{array}{l}\text { INF- } \\
\text { SUP }\end{array}$ & $\begin{array}{l}\text { Informal supervision: Carer spending time } \\
\text { supervising the person, making sure they are safe } \\
\text { and preventing any dangerous events e.g. } \\
\text { wandering. }\end{array}$ & $\begin{array}{l}£ 24 \text { per hour } \\
\text { weekday } \\
£ 25 \text { per hour } \\
\text { weekend }\end{array}$ & $\begin{array}{l}\text { Home care worker- based on the price } \\
\text { multipliers for independent sector home } \\
\text { care provided for social services. Face } \\
\text { to face contact. }\end{array}$ & $\begin{array}{l}\text { Unit Cost of Health and } \\
\text { Social Care } 2014 \text { (11.6, pg } \\
210)\end{array}$ \\
\hline
\end{tabular}


Table 4. Envisaged weekly inputs and costs for each service

\begin{tabular}{|c|c|c|c|c|}
\hline \multirow[t]{2}{*}{ Suggested service } & \multicolumn{2}{|c|}{$\begin{array}{l}\text { Suggested inputs } \\
\text { (hrs/week) } \\
\text { Mean(SD) }\end{array}$} & \multicolumn{2}{|c|}{$\begin{array}{c}\text { Costs (£/week) } \\
\text { Mean(SD) }\end{array}$} \\
\hline & $\begin{array}{c}\text { Staff } \\
(n=14)\end{array}$ & $\begin{array}{c}\text { Informal } \\
\text { carers } \\
(n=14)\end{array}$ & $\begin{array}{l}\text { Staff } \\
(n=14)\end{array}$ & $\begin{array}{c}\text { Informal carers } \\
(n=14)\end{array}$ \\
\hline \multicolumn{5}{|l|}{ Formal care } \\
\hline $\mathrm{HC}-\mathrm{P}$ & $32(24)$ & $18(11)$ & 761 (595) & $429(262)$ \\
\hline HC-D & $30(16)$ & $9(6)$ & $731(386)$ & $221(150)$ \\
\hline $\mathrm{HN}$ & $1(1)$ & $3(8)$ & $31(69)$ & $188(515)$ \\
\hline HN-D & $3(5)$ & $6(7)$ & $195(344)$ & $441(544)$ \\
\hline$\overline{D C G}$ & $4(9)$ & $22(27)$ & $51(111)$ & $262(320)$ \\
\hline DC-D & $47(19)$ & $51(32)$ & $568(226)$ & $618(385)$ \\
\hline HHCT & $1(1)$ & $3(3)$ & $19(47)$ & $101(138)$ \\
\hline $\mathrm{RC}-\mathrm{H}$ & $10(12)$ & $5(4)$ & $324(406)$ & $115(92)$ \\
\hline $\mathrm{HPC}-\mathrm{H}$ & $0(0.3)$ & $0(0)$ & $6(21)$ & 0 \\
\hline $\mathrm{HM}$ & $3(4)$ & $7(6)$ & $21(26)$ & $48(42)$ \\
\hline TR & $6(4)$ & $3(4)$ & 267 (189) & $146(201)$ \\
\hline$A C$ & $0(0)$ & $1(2)$ & $7(18)$ & $41(94)$ \\
\hline VO & $2(4)$ & $3(4)$ & $116(175)$ & $145(179)$ \\
\hline $\mathrm{SH}$ & $1(4)$ & $1(2)$ & 64 (199) & $36(86)$ \\
\hline CS & $3(3)$ & $4(6)$ & $150(119)$ & $203(287)$ \\
\hline OT & $.4(1)$ & 0 & $13(23)$ & 0 \\
\hline SPL & $.2(1)$ & 0 & $8(21)$ & 0 \\
\hline DIET & $.4(1)$ & $.1(.3)$ & $16(31)$ & $3(10)$ \\
\hline $\mathrm{CON}$ & $.3(1)$ & 0 & $21(54)$ & 0 \\
\hline $\mathrm{CH}$ & $48(103)$ & $36(97)$ & $215(547)$ & $161(436)$ \\
\hline Total & $196(97)$ & $172(83)$ & 3597 (1567) & 3169 (1311) \\
\hline \multicolumn{5}{|l|}{ Informal care } \\
\hline INF-P & $25(54)$ & $21(55)$ & 607 (1296) & $492(1330)$ \\
\hline INF-D & $52(72)$ & $20(59)$ & $1358(2247)$ & 468 (1404) \\
\hline INF-SUP & $55(74)$ & $41(141)$ & $1313(1776)$ & 994 (3377) \\
\hline Total & $132(179)$ & $81(245)$ & $3163(4303)$ & 1954 (5882) \\
\hline
\end{tabular}

Note: Figures are inputs/costs over the five case vignettes for the 14 participants from each perspective. The case vignettes are representative of $42 \%$ of people with dementia living at home but at risk of institutionalisation in the UK dataset. 
Table 5. Envisaged total inputs and costs: by formal staff and informal carers for each case type

\begin{tabular}{|c|c|c|}
\hline Case type (vignette) & $\begin{array}{c}\text { Suggested total inputs } \\
\text { (hrs/week) } \\
\text { Mean (SD) }\end{array}$ & $\begin{array}{c}\text { Costs (£/week) } \\
\text { Mean (SD) }\end{array}$ \\
\hline \multicolumn{3}{|l|}{ Formal staff } \\
\hline $1-$ Mrs. B & 77 (77) & $1853(1812)$ \\
\hline $2-M r s T$ & $81(42)$ & $1358(601)$ \\
\hline $3-M r . Q$ & $29(18)$ & $708(418)$ \\
\hline $4-$ Mrs. D & $67(85)$ & $1512(2064)$ \\
\hline $5-$ Mrs. C & $75(78)$ & $1329(1659)$ \\
\hline Total [across case types] & $328(154)$ & $6760(4006)$ \\
\hline \multicolumn{3}{|l|}{ Informal carers } \\
\hline $1-$ Mrs. B & $56(40)$ & $1027(582)$ \\
\hline $2-M r s \mathrm{~T}$ & $62(60)$ & $979(993)$ \\
\hline $3-M r . Q$ & $40(33)$ & $926(798)$ \\
\hline $4-$ Mrs. D & $36(41)$ & $795(956)$ \\
\hline $5-$ Mrs. C & $59(128)$ & $1386(3127)$ \\
\hline Total [across case types] & $253(256)$ & $5123(6276)$ \\
\hline
\end{tabular}

Note: Figures are inputs/costs for each case vignette, from the 14 participants from each perspective. The circumstances/characteristics? of each vignette are detailed in Table 2. 